\title{
Narrow Space of Deep Foundation Pit Engineering Design Study Bao-Xue SHAN ${ }^{1,2, a}$, Lu-Chao LIU,b, Jian-Nan LI,c \\ ${ }^{1,3}$ China University of Mining and Technology, Beijing, China ${ }^{2}$ China Xinxing Construction and Development General CO., Beijing, China asbx126.com@126.com, bliuluchao123@163.com, 'lijn_amber@qq.com
}

\section{Keywords: Deep Foundation Pit, Narrow Space, Common Mature Technology.}

\begin{abstract}
Combine with examples of successful projects, use of mature technology flexibly, analysis of narrow space of deep foundation pit engineering design, provide a reference for the design and construction of similar projects.
\end{abstract}

\section{Introduction}

Because of maximize the using of limited underground space in the city center, the space surrounding pit become more and more narrow. This gives deep foundation engineering design (design of shoring, excavation precipitation and draining design, etc.) and construction of many new challenges and higher demand.[1] The Narrow Space is refers to the space around the pit floor space and underground soil is relatively narrow.

How to use common scientific and rational mature technology, and to seek security, economic and efficient best combination of points, that is the evaluation excavation design the key to success lies. Following several engineering examples, let's talk about the design, applied research of urban narrow space excavation.

\section{Pit above-ground Evenly around the Narrow Circumstances}

Tennis court project of Beijing Shichahai Sports School, its foundation depth is $14.0 \mathrm{~m}$. Underground structure from the surrounding buildings, roads, pipe trench distance only about 1.3 meters. Field area stratigraphic which filled with miscellaneous soil, clay, silty clay, sandy soil and gravel soil interbedded thickness is range from 1.5 to $4.5 \mathrm{~m}$. In view of the pit close to the surrounding buildings and facilities, and limited slope deformation strictly for ensure safety, it should adopt higher security the inner support program or pile anchor scheme.

After discussion, the support program was first ruled out, because the total project duration is shorter, and the tennis court's underground wall is $10.0 \mathrm{~m}$ high, the use of the support scheme is not only can't be completed on schedule, but also can't change support in tying he tall wall bars, pouring concrete.

But the pile-anchor program, it is also quite difficult between solve conflicts structural construction and the foundation pit system : on the one hand, by the space limitations, can not use rig piling, the fat groove surplus width of hand-dug piles less than $200 \mathrm{~mm}$, the steel I-beam and anchor head occupied width of at least $400 \mathrm{~mm}$, so that when the height of the structure exterior wall construction near the bolt, the steel I-beam and anchor head must be removed; the other hand, due to the underground wall of tennis is 10.0 meters high, in this height range is no vertical walls , floors and other interior structure to support exterior walls, if you remove the steel beams and anchor head, enormous pressure will cause the soil slope and underground exterior walls severely deformed and damaged. So how to reduce the space occupied by the anchor head and steel beams without removing them is a big problem in foundation pit support design of this project. During the study, we considered to lock bolt on the slope Piles directly, cancel steel I-beams. Fix pipe on the steel reinforcement cage of Slope Protection pile, pre-burying in concrete as holes for anchor construction. Or use the alloy drilling to drill anchor holes on slope protection pile. But the method is not only make the piles strength and flexural capacity decrease because of the piles left holes , 
there is no structural steel beams can be connected into a whole pile anchor, branch retaining the overall coordination role of retaining structure obviously deteriorated, but also the construction of this method is difficult, we can not control accurately.

Finally, after repeated study and combined with mature experience, we decided to use channel instead of the I-beam , and make channel steel embed in the soil between piles Wall layer, anchor head placed in the channel groove, so that the anchor head and steel I-beams occupied fat groove width not exceeding $100 \mathrm{~mm}$. Underground structures waterproof layer can be affixed to the anti-endothelial supporting structure, in order to ensure tied up the big wall bars disposably, poured concrete construction smoothly. To overcome low intensity and poor resistance to deformation of the channel beam, can be taken to increase the number of prestressed anchor rows, and also can use this technical measures that reduce the tension of each row of bolt (the bolt tension control within the limits of $150 \mathrm{KN}$ ). In order to enhance the effect of contact with the slope protection pile, so that the role of the anchor to pull into full play, we can add reinforced concrete panels between steel beams and piles (and between piles of soil), it is similar to reinforced concrete surface layer of soil nail wall and strengthen appropriate reinforcement anchor head parts. Specifically see the following figures:

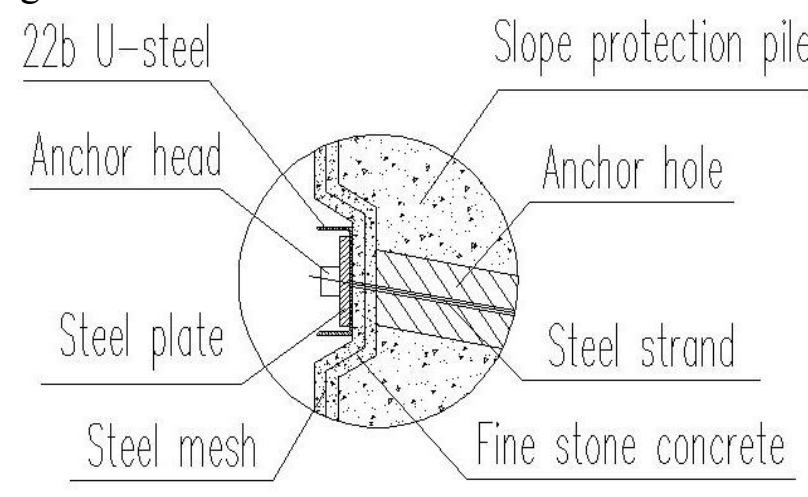

Fig. 1 Pile Anchor Head Detail Drawing

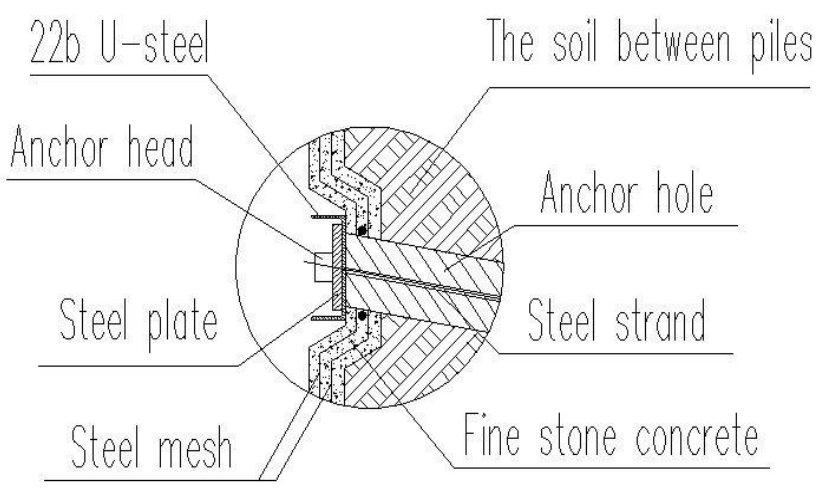

Fig. 2 Soil Anchor Head Detail Drawing

The project of foundation pit supporting design not only successfully solved the problems of fat narrow slot, but also has higher security. When the pit foundation engineering was Just finished in the summer of 2009, a sudden rainstorm will rain trench adjacent half way down,a lot of rain instantly filled with foundation pit. the relevant department called a large number of pumping equipment and used two days and nights to draining pit after danger the occur, the supporting system of foundation pit is almost intact ,the deformation of the foundation pit and its adjacent building monitoring data are within the scope of the permit, so this project got high praise.

In order to further reduce the project cost, this paper use top straight slope soil nail wall (or composite soil nailing wall) combined with lower the pile anchor supporting structure for small surface load slope. Supporting form is shown as in the figure below.

Of course, for this kind of foundation pit, narrow around the floor space well underground space project. Has good properties such as soil, slope load is small, not very strict with the deformation of deep foundation pit engineering, can adopt high efficiency of large slope form of composite soil nailing.

The floor space around the foundation pit is narrow, this not only make supporting structure limited, precipitation engineering is also difficult to implement. Occurrence in thick gravel layer of underground water, confined water, using water underground continuous wall construction not only is difficult, and the project cost is very expensive, is rarely used in the Beijing area. Using high pressure jet grouting pile and slope protection pile form a combined method of water stop stop water heavy curtain construction difficulties still exist, check water effect is poor, the problem of high cost; And the commonly used foundation pit pumping around the tube well closed down is the most effective way. But if lack of outside the foundation pit precipitation tube well operation space, this method seems to be difficult to achieve, at this time can be a little flexible, will play in the 
foundation pit dewatering well, problem is solved, and of course in order to guarantee the effect of precipitation, precipitation well should be close to the slope.

If set a lot of worry about the foundation pit dewatering well, uniformity, the bearing capacity of foundation and base plate, waterproof construction have an impact, can draw lessons from "012 project" processing method: will remain in borehole water pump, a pump connected to the water pump from under the foundation pad to foundation pit slope upward again lead to foundation pit drainage; Precipitation since the end of the use of the embedded grouting pipe and exhaust pipe with straws will hole slurry closed, particular way is shown as below.

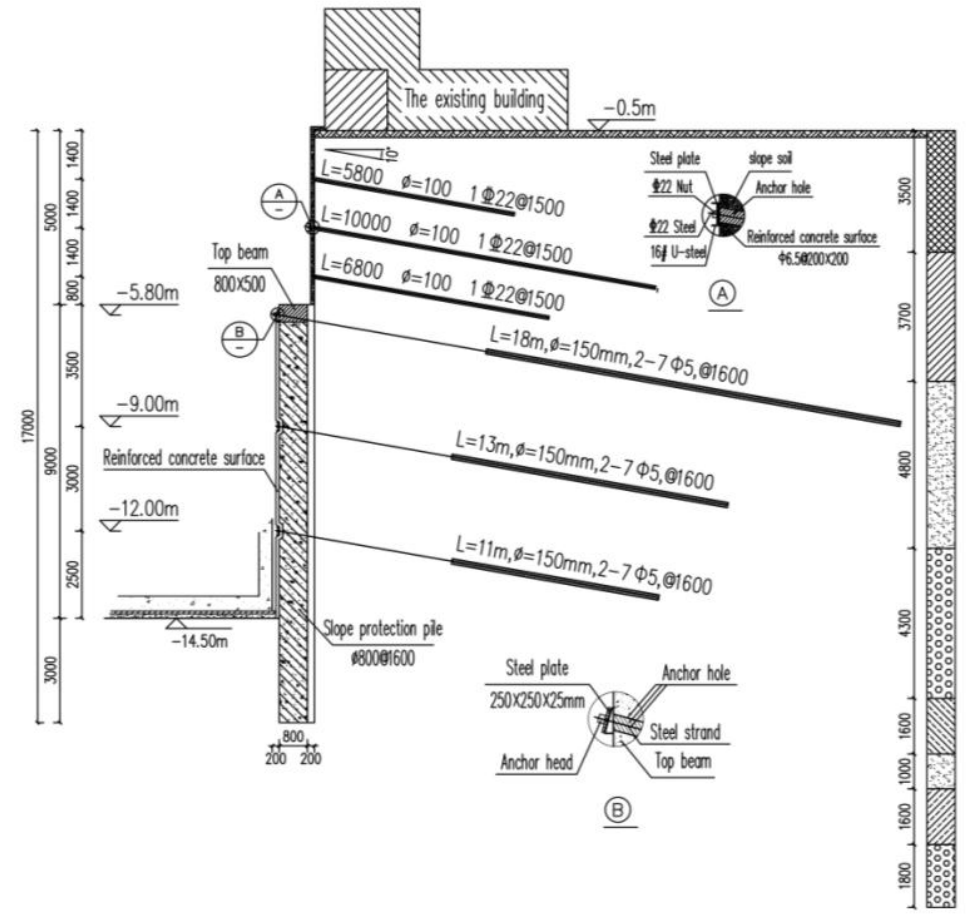

Fig. 3 Sectional Drawing of Foundation Pit Support

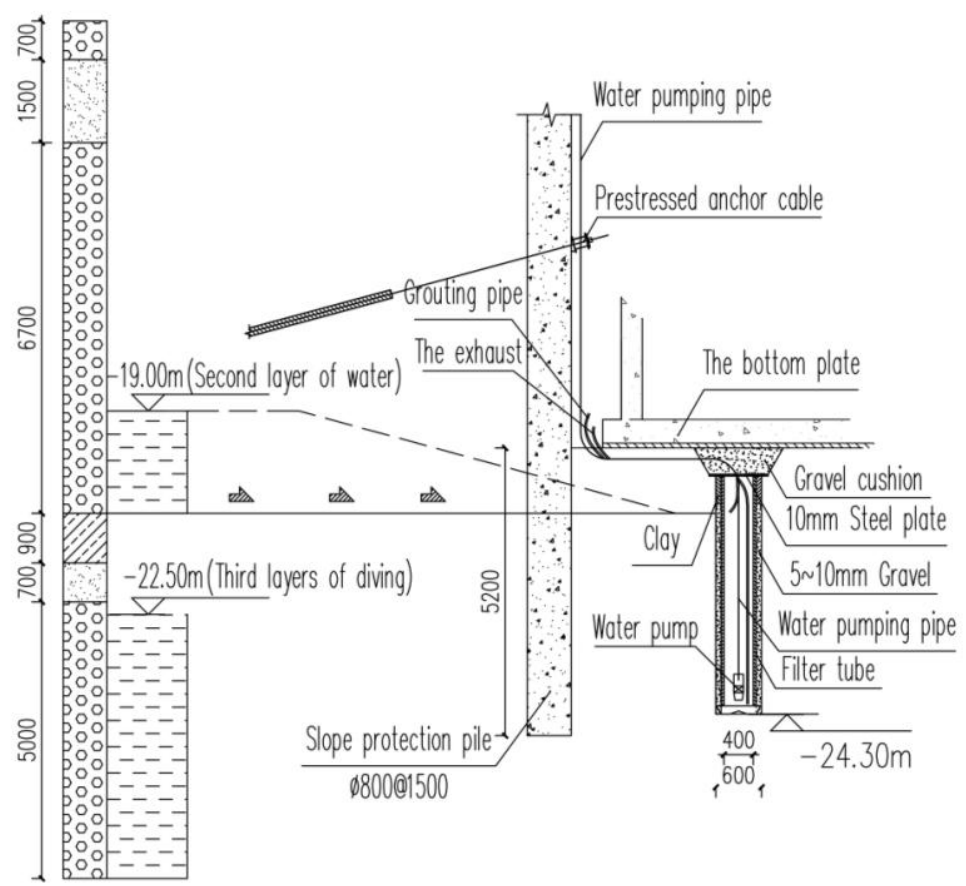

Fig. 4 Sectional Drawing of Foundation Pit Dewatering 
On the one hand, this method successfully reduced the groundwater in the foundation pit. During the dewatering engineering maintenance, it ensures the normal construction of foundation cushion, floor, waterproof engineering. On the other hand, this method did not leave a hole in the floor, reduces the construction difficulty, ensure the construction quality, also improve the efficiency of the construction. And dewatering well through grouting seal processing, can eliminate the potential safety hazard caused by local cavity of foundation soil.

\section{The Foundation Pit of Underground Space are Narrow}

The adjacent foundation pit around underground structures (basements, underground facilities, structures, etc.).The slope soil is narrow column. If the slope soil is don't need to keep, appropriate unloading processing (upper unloading or whole unloading).It is advisable to unload (upper unloading or whole unloading). Once the slope soil needs to be preserved. This will increase the difficulty of the supporting design of slope. At first, according to the theoretical calculation and ripe experience, the soil pressure in soil slope should be reduced, causing a certain degree of reduce the strength of supporting structure. Then should be to study the soil potential damage factors and damage location. Finally considering all kinds of the applicability of the supporting structure. Combined with engineering characteristics make targeted supporting and with strong feasibility design.

For underground structures around the embedment depth is higher than the new excavation of basement, we should make full use of the underground structure under soil space around. And should make full use of the soil space under the around underground structure, to set the high strength of anchoring-drawing structure. In order to improve the safety of the whole supporting structure. For the upper of the soil column, should give priority to with reinforced soil to improve the stability of the soil itself. Common reinforcement methods are soil nail, bolt reinforcement and grouting reinforcement, etc. Specific supporting design, see the below graphic.(Jingxi hotel garage foundation pit supporting section)

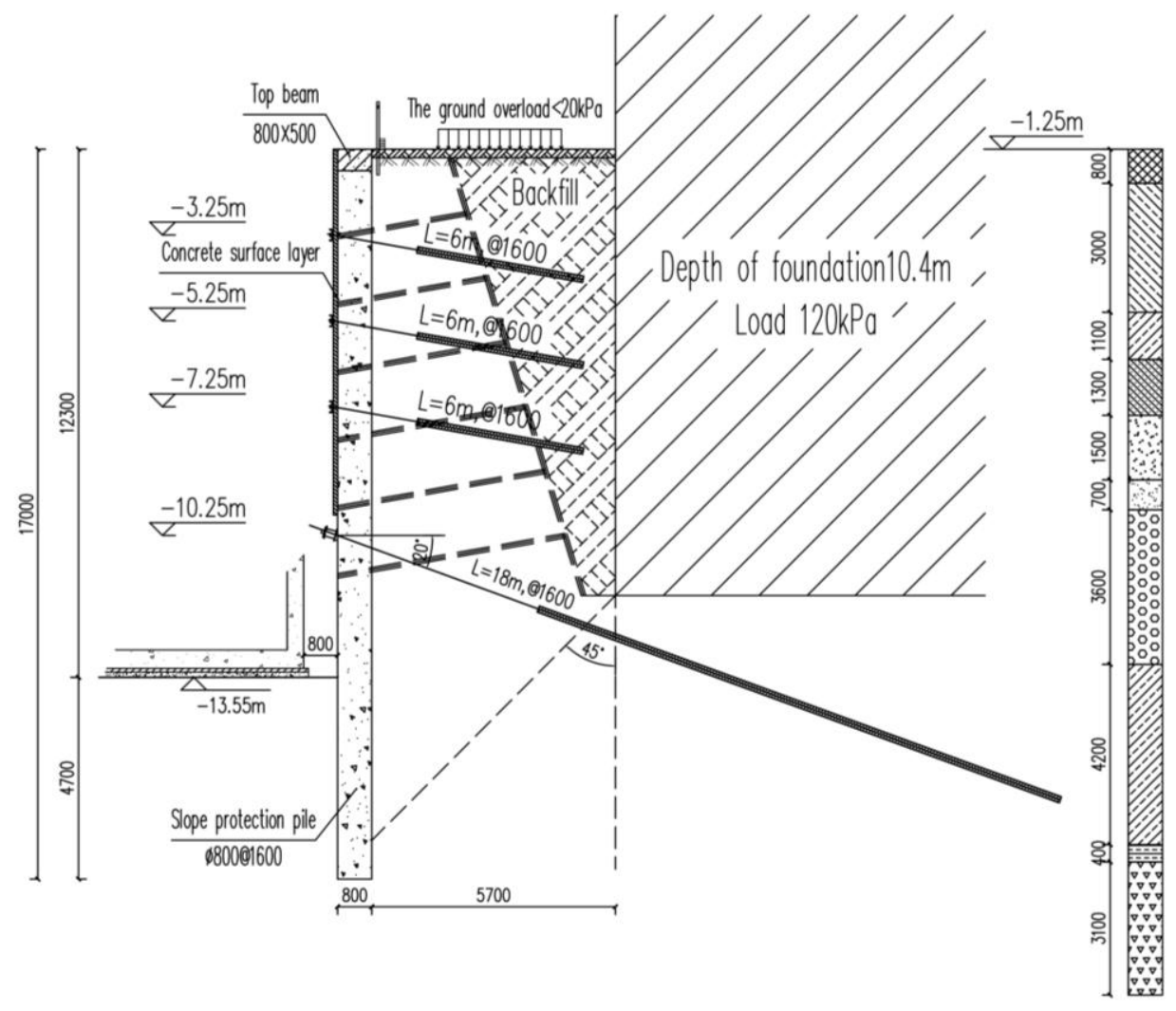

Fig. 5 Jingxi Hotel Garage Foundation Pit Supporting Section 
For underground structures around the embedment depth is below the new excavation of basemen. If the depth of foundation pit is deep, appropriate uses retaining structure with double-row piles in order to improve the stability of the slope. Below is the success of the double row pile foundation pit supporting case of Rongke Info Centre.

Of course, for the foundation pit slope as the column of soil, also can use safe and reliable inner supporting structure, But the economy and convenient construction based on the consideration of soil nature, relatively good slope pile anchor structure is always the preferred scheme. The inner supporting structure for foundation pit excavation, slope usually narrow poor engineering properties of soil and the strict requirements on the slope deformation of foundation pit.

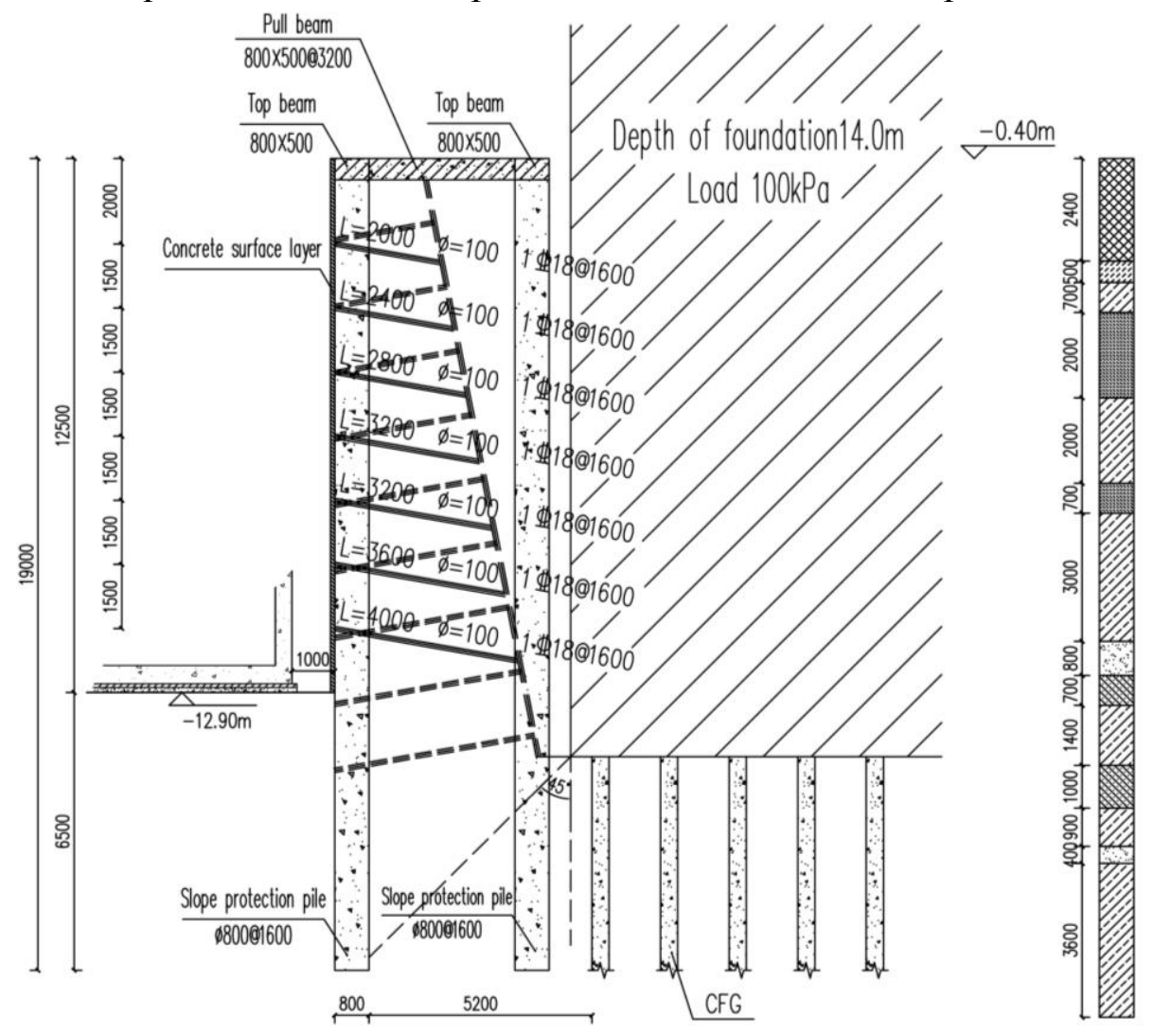

Fig. 6 Double Row Pile Foundation Pit Supporting Case of Rongke Info Centre

\section{Conclusion}

With the rapid development of our country city changes a course, in the height of the building is growing at the same time, the underground structure in depth and width is also continuing extension, influence of surrounding ground, underground environment becomes more and more complex. How to use the limited underground space on the ground, the foundation pit engineering design science reasonable, but people continue to explore and innovation impetus and opportunity and achieve the best effect of safety, economy and high efficiency.[2] These successful cases may provide some reference for the similar foundation pit engineering design.

\section{References}

[1]Zhao Hua-Li, Fu Shao-Jun, The Current Situation and Development of Deep Foundation Pit [J], Jouranal of XiaoGan University. 2005. 25(3). 94 96.

[2]Liu Er-shuan, The Characteristics and Problems of Deep Foundation Pit Engineering, Nonferrous Metals Design. 2004. 31(1):45 47. 